\title{
GLICEROQUÍMICA: NOVOS PRODUTOS E PROCESSOS A PARTIR DA GLICERINA DE PRODUÇÃO DE BIODIESEL
}

\author{
Claudio J. A. Mota,* Carolina X. A. da Silva e Valter L. C. Gonçalves
}

Instituto de Química, Universidade Federal do Rio de Janeiro, Av. Athos da Silveira Ramos, 149, CT, Bl. A, 21941-909 Rio de Janeiro - RJ, Brasil

Recebido em 16/1/09; aceito em 11/3/09; publicado na web em 25/3/09

\begin{abstract}
GLYCEROCHEMISTRY: NEW PRODUCTS AND PROCESSES FROM GLYCERIN OF BIODIESEL PRODUCTION. Glycerol is a byproduct of biodiesel production through transesterification of oils and fat. This article discusses the chemical transformation of glycerol in ethers, acetals and esters of high technological applications, especially in the fuel sector. Glycerol hydrogenolysis, dehydration to acrolein and oxidation are discussed as well, to show the potential use of glycerol for production of plastic monomers. Finally, the article shows other transformations, such as syn gas production, epichloridrin and glycerin carbonate.
\end{abstract}

Keywords: glycerol; biodiesel; transesterification.

\section{BIODIESEL E MERCADO DA GLICERINA}

O século XX pode ser caracterizado como o século do petróleo. A sociedade moderna acostumou-se a desfrutar do conforto oferecido por esta matéria-prima não renovável, na forma de combustíveis e produtos químicos de uso diário, como os plásticos. Derivados do petróleo, esta nova classe de materiais tem sido largamente utilizada desde meados do século passado, substituindo a madeira, os metais e até mesmo o concreto, dando início ao que chamamos de petroquímica. ${ }^{1}$

No entanto, o constante aumento da demanda por fontes de energia, as mudanças climáticas causadas pelo aquecimento da atmosfera e o esgotamento das reservas de petróleo de fácil extração, aliado a um desenvolvimento socioeconômico mais intenso, sobretudo nos países em desenvolvimento, têm incentivado a utilização de insumos renováveis, que possam substituir, ao menos parcialmente, os combustíveis de origem fóssil como petróleo, carvão e gás natural. O limite ao uso dos combustíveis fósseis não vai se dar somente pelo esgotamento das reservas, mas também pela redução da capacidade ambiental do planeta de absorver os gases oriundos de sua combustão.

O transporte é um dos maiores responsáveis pela emissão de poluentes atmosféricos, uma vez que depende da combustão de derivados do petróleo como gasolina e óleo diesel. De toda energia primária consumida no mundo em 1999, 43\% veio do petróleo, e desta parcela, 58\% destinou-se ao setor de transporte. ${ }^{2}$ Em 2003, cerca de $50 \%$ da energia consumida no país proveio de fontes fósseis, como óleo e seus derivados. O transporte foi a origem de praticamente metade desse total.

As crescentes emissões de dióxido de carbono oriundas da queima de combustíveis fósseis estão alterando o clima global. Se nada for feito para conter o aquecimento da atmosfera, até o fim do século XXI teremos mudanças significativas no nível dos mares, que irá afetar toda a vida na Terra. Uma das alternativas mais prementes para minimizar este problema são os biocombustíveis. Por terem origem vegetal, eles contribuem para o ciclo do carbono na atmosfera e por isto são considerados renováveis, já que o $\mathrm{CO}_{2}$ emitido durante a queima é reabsorvido pelas plantas que irão produzi-lo, causando um impacto muito menor no aquecimento do planeta, pois no balanço total diminuem as emissões de $\mathrm{CO}_{2}$. O Brasil é um dos pioneiros no uso deste tipo de combustível já utilizando o álcool etílico, oriundo da fermentação da cana, desde a década de 1970.

*e-mail: cmota@iq.ufrj.br
Além das questões globais, os biocombustíveis apresentam vantagens relativas ao meio ambiente local. Por não possuírem enxofre em sua composição, sua queima não provoca emissão de óxidos de enxofre $\left(\mathrm{SO}_{2}\right.$ e $\left.\mathrm{SO}_{3}\right)$, poluentes danosos à qualidade do ar e responsáveis pela chamada chuva ácida.

$\mathrm{O}$ uso de óleos e gorduras de origem vegetal ou animal como combustível remonta ao fim do século XIX, quando Rudolph Diesel, inventor do motor à combustão interna que leva seu nome, utilizou em seus ensaios petróleo cru e óleo de amendoim. Devido ao baixo custo e alta disponibilidade do petróleo à época, este passou a ser o combustível largamente usado nestes motores. ${ }^{3}$ Com o passar do tempo, tanto o motor quanto o combustível foram ajustados, buscando maior eficiência e menor custo, a tal ponto que, atualmente, não é mais possível utilizar petróleo cru ou óleos vegetais in natura diretamente.

Recentemente, o biodiesel surgiu como uma alternativa viável em termos de combustível renovável. . $^{4}$ A principal rota de obtenção do biodiesel é a partir da transesterificação de óleos vegetais com álcoois (metanol e etanol), usando catálise básica (Figura 1).

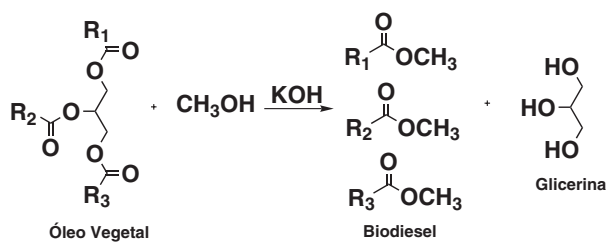

Figura 1. Produção de biodiesel a partir da transesterificação de óleos vegetais

Do ponto de vista químico, o óleo vegetal usado na produção de biodiesel é um triglicerídeo, ou seja, um triéster derivado da glicerina. Sob ação de um catalisador básico e na presença de metanol ou etanol, o óleo sofre uma transesterificação formando três moléculas de ésteres metílicos ou etílicos dos ácidos graxos, que constituem o biodiesel em sua essência, e liberando uma molécula de glicerol ou glicerina.

Em 2004, o Governo Federal instituiu o Programa Nacional de Produção e Uso do Biodiesel, que prevê que este biocombustível seja adicionado ao diesel fóssil. Em 2008, o diesel comercializado em todo território nacional passou a conter, obrigatoriamente, $3 \%$ de biodiesel (B3). Em 2013 está previsto o aumento deste percentual 
para 5\% (B5), mas o governo em diversas ocasiões, já manifestou a possibilidade de antecipação destas metas. Se, por um lado, estas ações colocam nosso país na vanguarda do uso de combustíveis alternativos no planeta, elas também reforçam a necessidade de se encontrar utilizações comerciais para os coprodutos de produção do biodiesel, como a glicerina. Para cada $90 \mathrm{~m}^{3}$ de biodiesel produzidos por transesterificação são gerados, aproximadamente, $10 \mathrm{~m}^{3}$ de glicerina. Assim, as projeções mostram uma produção de cerca de 100 mil toneladas de glicerina por ano com a entrada do B3 em 2008 e cerca de 250 mil toneladas a cada ano, a partir de 2013, com a introdução do B5. Estes valores são muito superiores ao consumo e produção nacional atuais, estimados em cerca de 30 mil toneladas anuais. ${ }^{6}$ Este cenário indica que a viabilização comercial do biodiesel passa pelo consumo deste volume extra de glicerina, buscando aplicações de larga escala e agregando valor à cadeia produtiva.

O glicerol foi primeiramente descoberto em 1779 por Scheele, pelo aquecimento de uma mistura de óxido de chumbo com azeite de oliva. Na época, ele o batizou de "o doce princípio das gorduras". $\mathrm{O}$ glicerol ocorre naturalmente em formas combinadas, como nos triglicerídeos, em todos os óleos graxos animais e vegetais, sendo isolado quando estes óleos são saponificados com hidróxido de sódio ou potássio, no processo de manufatura de sabões. Desde 1949, o glicerol também tem sido produzido comercialmente pela síntese do propeno (Figura 2). A etapa inicial é a cloração a alta temperatura, envolvendo radicais livres como intermediários, para formar o cloreto de alila. Este é então reagido com ácido hipocloroso (água sanitária) dando um produto de adição à dupla (haloidrina). Por fim, o tratamento da haloidrina com excesso de base leva ao glicerol. Esta rota representa atualmente $25 \%$ da capacidade de produção dos EUA e 12,5\% da capacidade de produção mundial, mas muitas unidades estão sendo desativadas em virtude da grande oferta de glicerol oriundo da produção de biodiesel. Estima-se que em todo o mundo a produção de glicerol alcançará 1,2 milhões de toneladas ${ }^{7}$ por volta de 2012 , devido ao aumento da produção de biodiesel.

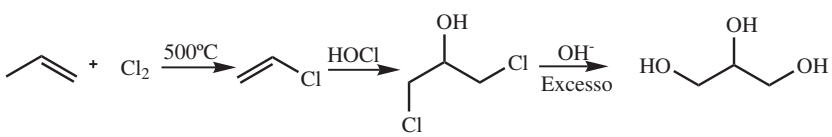

Figura 2. Rota industrial de produção de glicerina a partir do propeno

O termo glicerol aplica-se somente ao componente químico puro 1,2,3-propanotriol. O termo glicerina aplica-se aos produtos comerciais purificados, normalmente, contendo pelo menos $95 \%$ de glicerol. Vários níveis e designações de glicerina estão disponíveis comercialmente. Eles diferem um pouco em seu conteúdo de glicerol e em outras características, tais como cor, odor e impurezas. ${ }^{8}$ A chamada glicerina loira é normalmente utilizada para designar a glicerina oriunda dos processos de produção do biodiesel, onde a fase glicerinosa sofreu um tratamento ácido para neutralização do catalisador e remoção de ácidos graxos eventualmente formados no processo. Em geral, esta glicerina contém cerca de $80 \%$ de glicerol, além de água, metanol e sais dissolvidos.

A glicerina purificada (grau USP ou glicerina farmacêutica) tem grande aplicação nos setores de cosméticos, higiene pessoal, alimentos, medicamentos e fumo. Em termos de transformação química ela ainda apresenta aplicações limitadas, sendo as principais na produção de explosivos, como a nitroglicerina, e na formação de resinas alquídicas. A Figura 3 mostra uma distribuição percentual de aplicações mais usuais da glicerina. Neste trabalho abordaremos algumas transformações químicas possíveis para a glicerina, visando a utilização como matéria-prima para a produção de insumos da cadeia petroquímica (plásticos) e produtos com aplicações no setor de combustível.

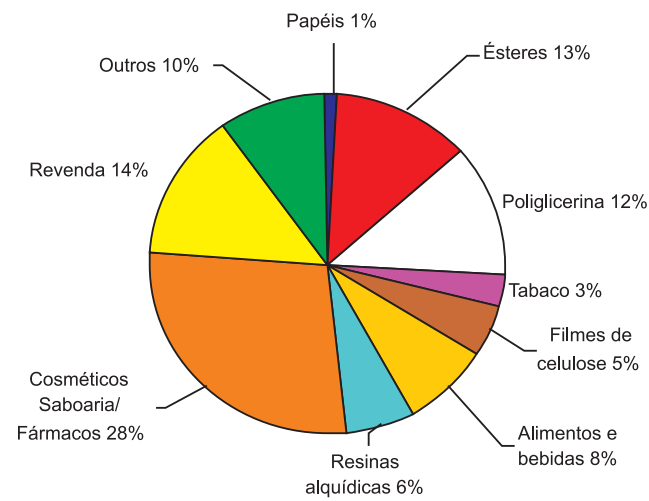

Figura 3. Principais setores industriais de utilização da glicerina

\section{ACETAIS DA GLICERINA}

Acetais e cetais são substâncias obtidas da reação de álcoois com aldeídos ou cetonas, respectivamente, sob ação de catalisadores ácidos. Os cetais e acetais derivados do glicerol têm aplicações diversas, destacando-se o uso como aditivo para combustíveis, ${ }^{9,10}$ surfactantes, ${ }^{11}$ flavorizantes ${ }^{12}$ e solventes para uso em medicina. ${ }^{13}$

Deutsch e colaboradores ${ }^{14}$ estudaram a condensação do glicerol com benzaldeído catalisada por sólidos ácidos, como a resina Amberlyst-36, zeólita H-Beta e arila K-10 (montmorilonita), utilizando solventes como benzeno, tolueno, clorofórmio e diclorometano, para remoção da água formada. A acetalização é reversível e a remoção da água do meio ajuda a aumentar o rendimento. Após $2 \mathrm{~h}$ de reação eles conseguiram entre 80 a $94 \%$ de rendimento nos acetais, dependendo do catalisador e solvente empregados. O procedimento também funcionou para a reação do glicerol com acetona e formaldeído, mas os rendimentos foram um pouco menores no caso do formaldeído, provavelmente devido ao excesso de água no meio reacional, já que eles utilizaram uma solução a 37\%. Nas reações com benzaldeído foram produzidas misturas dos acetais [1,3]-dioxan-5-ol (Z e E) e [1,3]-dioxolan-4-metanol (Z e E) (Figura 4). A proporção variou com o tempo de reação, mostrando que pode haver interconversão das espécies no meio reacional. Mota e colaboradores ${ }^{15}$ utilizaram uma zeólita Beta de alta razão $\mathrm{Si} / \mathrm{Al}$ de rede na reação do glicerol com formaldeído, obtendo conversão acima de $90 \%$ e sem a necessidade do uso de solventes (Figura 5). Comparativamente a outros catalisadores ácidos, como resina Amberlyst-15, zeólitas H-USY e H-ZSM-5, argila K-10 e até mesmo o ácido p-tolueno-sulfônico, a zeólita H-Beta tem uma melhor performance, pois o ambiente dos seus poros é hidrofóbico, devido à alta razão Si/Al. ${ }^{16}$ Isto faz com que a água do meio reacional não difunda facilmente para o interior dos poros, preservando a força dos sítios ácidos. A água formada na reação também é expulsa mais facilmente do interior das cavidades, deslocando o equilíbrio da reação. A zeólita USY possui uma razão $\mathrm{Si} / \mathrm{Al}$ de rede bem menor e é hidrofílica, tendo, possivelmente, sua acidez enfraquecida pela presença de excesso de água no meio reacional. Já a ZSM-5, apesar da alta razão Si/Al de rede, tem poros menores, que dificultam a formação do produto, efeito conhecido como seletividade de forma. ${ }^{17}$

As reações do glicerol com aldeídos, em geral, fornecem dois acetais; um com anel de 5 membros e outro com anel de 6 membros. Já nas reações com cetonas, forma-se quase que exclusivamente o cetal com anel de 5 membros. Não existem estudos sistemáticos na literatura sobre este comportamento. Uma possibilidade ${ }^{15}$ é que na reação com cetonas, como acetona, a desidratação do hemicetal ocorra 


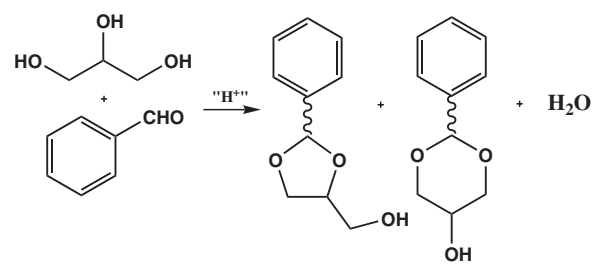

Figura 4. Reação do glicerol com benzaldeído. Formação de acetais

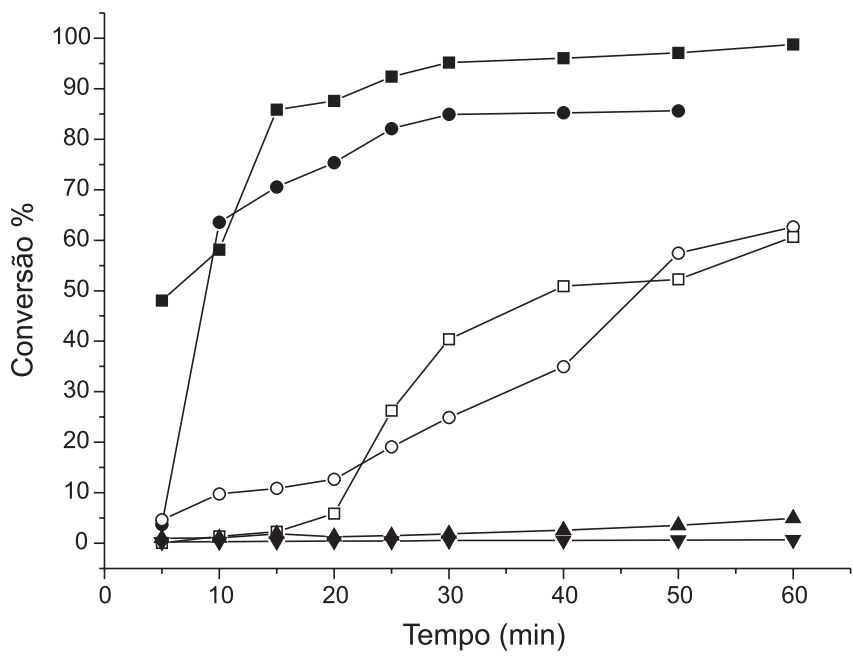

Figura 5. Conversão do glicerol na reação com solução de formaldeido sobre ação de diferentes catalisadores ácidos ( $\mathbf{\square})$ zeólita H-Beta, (•) ác-p-toluenosulfônico, ( $\square$ ) resina ácida Amberlyst-15, (○) argila K-10, (ム) zeólita H-USY, ( $)$ zeólita H-ZSM-5

com a formação de um carbocátion terciário, que é rapidamente atacado pela hidroxila central, formando o cetal com anel de 5 membros (Figura 6). É conhecido na literatura que a ciclização para formação de anéis de 5 membros é cineticamente mais favorecida em relação à formação de anéis de 6 membros. ${ }^{18}$ Assim, uma vez formado o carbocátion ele sofre o ataque nucleofílico para formar o produto de controle cinético. Já com os aldeídos, como o formaldeído, a desidratação do hemiacetal se dá por um mecanismo $\mathrm{S}_{\mathrm{N}} 2$, onde a saída da água ocorre simultaneamente ao ataque nucleofílico (Figura 7). Isto permitiria uma reorganização estrutural levando aos produtos de controle cinético (acetal com anel de 5 membros) e termodinâmico (acetal com anel de 6 membros).

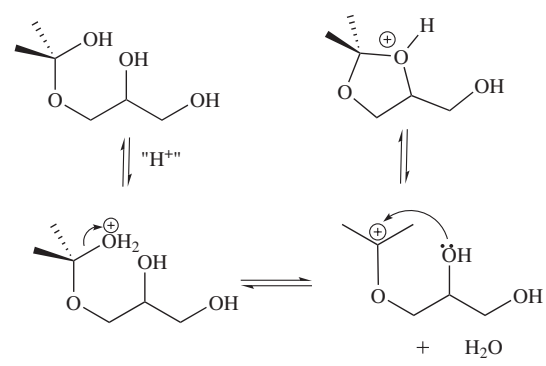

Figura 6. Possível mecanismo para formação do cetal de glicerol/acetona

Os acetais da glicerina têm potencial para mistura com combustíveis. Os derivados produzidos nas reações com formaldeído e acetona podem ser misturados à gasolina, melhorando as propriedades de queima. ${ }^{19} \mathrm{O}$ acetal produzido na reação do glicerol com acetona foi também testado em misturas com biodiesel. ${ }^{20}$ Os resultados mostraram que ele diminui o ponto de fulgor do biodiesel abaixo do limite estabelecido pela União Européia, assim como pode sofrer hidrólise,

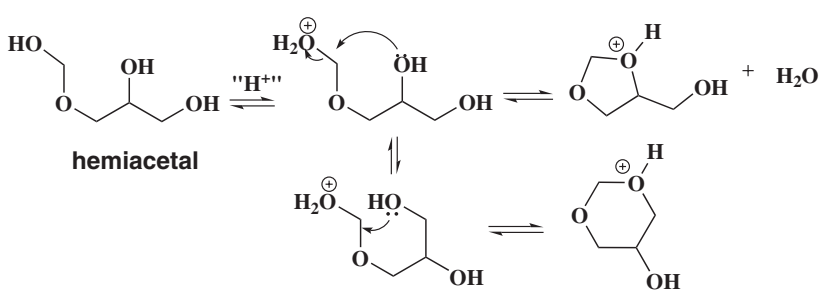

Figura 7. Possível mecanismo para formação dos acetais de glicerol/formaldeído

levando à contaminação do biodiesel por glicerol. Esta hidrólise pode estar sendo favorecida pela presença da hidroxila livre do cetal, que aumentaria a solubilidade da água na mistura com biodiesel. De fato, a funcionalização da hidroxila livre ${ }^{20}$ diminui sensivelmente a hidrólise, evidenciando o papel deste grupo nas propriedades da mistura cetal/ biodiesel. Os acetais formados na reação com butiraldeído podem ser utilizados como aditivos ao diesel, diminuindo em cerca de $20 \%$ a emissão de particulados. ${ }^{21}$

A polaridade e aplicabilidade dos acetais e cetais do glicerol podem ser modificadas pela funcionalização da hidroxila remanescente. Reações com agentes alquilantes ou acilantes levam à formação de compostos multifuncionalizados com aplicações diversas. ${ }^{22,23}$ A fosforilação da hidroxila livre leva a compostos com atividade bactericida. $^{24}$

\section{PRODUÇÃO DE ÉTERES DE GLICERINA}

A eterificação do glicerol produz compostos de menor polaridade e viscosidade e, por conseguinte, de maior volatilidade. Isto faz com que os éteres do glicerol tenham inúmeras aplicações, sobretudo como aditivos para combustíveis e solventes.

O principal método de eterificação do glicerol é a reação com alquenos, catalisada por ácidos (Figura 8). Klepacova e colaboradores $^{25}$ avaliaram a eterificação do glicerol com isobuteno catalisada por resinas ácidas do tipo Amberlyst e pelas zeólitas de poros grandes, HY e H-BEA (zeólita Beta). Os resultados de conversão e seletividade foram melhores quando se utilizaram as resinas ácidas, em função do largo diâmetro dos poros. Karinen e Krause ${ }^{26}$ otimizaram as condições de reação entre glicerol e isobuteno, variando a razão molar dos reagentes. O mono e di t-butil-glicerol éteres são os produtos principais para razões molares isobuteno/glicerol menores que 3 . $\mathrm{O}$ tri-t-butil-glicerol éter só começa a ser formado em proporções significativas para razões molares acima de 4. Entretanto, ocorre significativa oligomerização do isobuteno nestas condições. Em al-

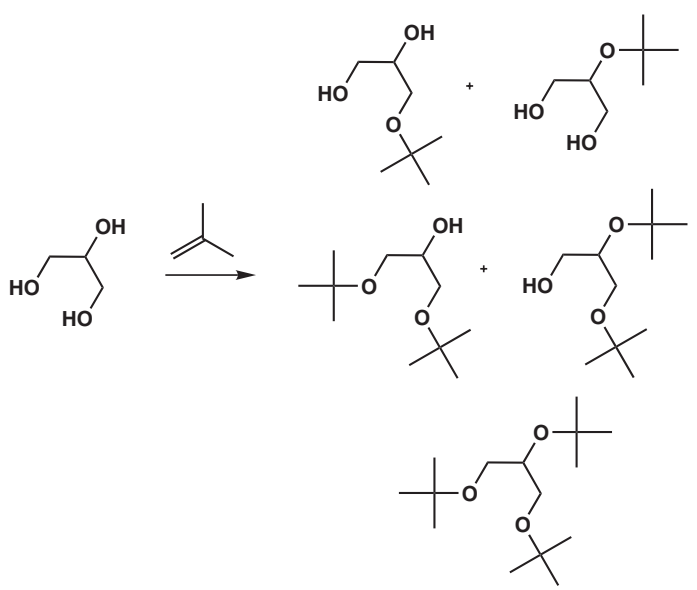

Figura 8. Esquema de reação da eterificação do glicerol com isobuteno 
guns experimentos foi adicionado álcool t-butílico (TBA) na mistura reacional com a finalidade de prevenir a reação de oligomerização e melhorar a seletividade ao tri-éter. Por outro lado, a eterificação do glicerol com álcool t-butílico leva a uma menor conversão, em função da água formada, que enfraquece os sítios ácidos do catalisador. ${ }^{27}$

A eterificação do glicerol com alcoóis primários e secundários é bem menos estudada na literatura. Mota e colaboradores estuda$\operatorname{ram}^{28}$ a eterificação do glicerol com álcool benzílico sobre diferentes catalisadores ácidos. Os melhores resultados foram obtidos com o uso de resina ácida Amberlyst-35 e zeólita H-Beta, que se mostrou bastante seletiva ao mono-éter. Além dos éteres do glicerol foi observada a formação do di-benzil-éter, oriundo da autoeterificação do álcool benzílico, devido ao excesso utilizado. Gu e colaboradores ${ }^{29}$ estudaram a eterificação do glicerol com 1-fenil-1-propanol sobre diversos catalisadores sólidos ácidos. Os melhores resultados foram com sílica funcionalizada com grupos sulfônicos $\left(\mathrm{SiO}_{2}-\mathrm{SO}_{3} \mathrm{H}\right)$, sendo obtidos primordialmente os derivados monoéteres. O mesmo catalisador foi utilizado na eterificação do glicerol por diversos outros alcoóis. Na reação com o 1,3-difenil-2-propanol eles obtiveram $96 \%$ de rendimento do monoéter e com isoborneol o monoéter foi isolado em $83 \%$ de rendimento. Forma-se uma mistura do 1-alquil e 2-alquilglicerol éter, com predominância do primeiro. Com alcoóis primários o rendimento é significativamente menor. O 2-octen-1-ol reagiu com o glicerol para formar o monoéter em $61 \%$ de rendimento após 39 h de reação a $80^{\circ} \mathrm{C}$, enquanto o álcool laurílico (n-dodecanol) foi inativo na reação, mesmo após $48 \mathrm{~h}$. A reação do glicerol com etanol e metanol foi realizada na presença de sólidos ácidos, produzindo mono, di e triéteres em função da quantidade molar do álcool/glicerol. ${ }^{30}$ Os éteres oriundos da reação do glicerol com etanol (Figura 9) têm grande potencial de aplicação em mistura com combustíveis, já que são formados a partir de matérias-prima renováveis.

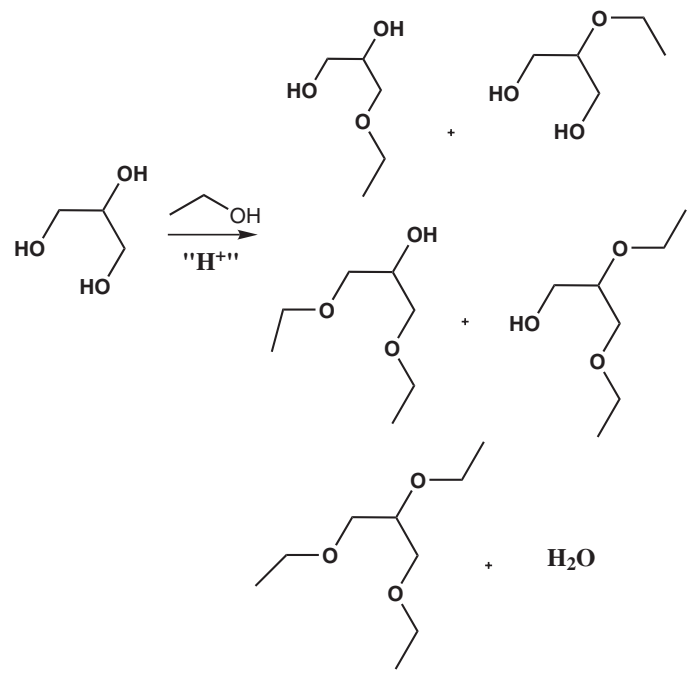

Figura 9. Eterificação do glicerol com etanol catalisada por sólidos ácidos

A síntese de Williamson, ${ }^{31}$ envolvendo alcóxidos e agentes alquilantes, como halogenetos de alquila, também pode ser utilizada para a preparação de éteres do glicerol. Mota e colaboradores ${ }^{32}$ estudaram a metilação do glicerol com cloreto e sulfato de metila, otimizando a preparação do 1,2,3-trimetóxi-propano (Figura 10). O procedimento geral consistiu em reagir o glicerol com solução alcalina para remover os prótons ácidos ligados à hidroxila, e na sequência adicionar o cloreto ou sulfato de metila, usando-se quantidades molares para trimetilação. O mais interessante nesses estudos é que a utilização da glicerina bruta, vinda da produção de biodiesel e sem qualquer tratamento prévio, leva a excelentes resultados, com formação do 1,2,3-trimetoxi-propano em cerca de 20 min de reação (Figura 11). A alcalinidade da glicerina bruta é fundamental nesta reação e o produto pode ser posteriormente isolado do meio por destilação à pressão reduzida. Os sais gerados na reação (cloreto ou sulfato de potássio) podem ser isolados do meio e usados como fertilizantes.

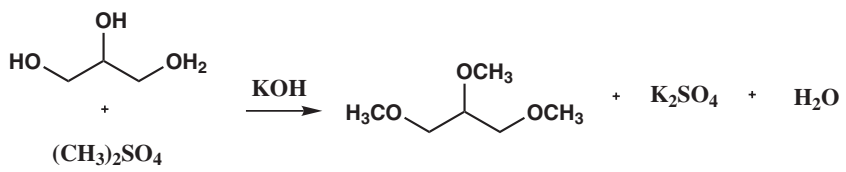

Figura 10. Eterificação do glicerol com sulfato de metila. Formação do 1,2,3-trimetóxi-propano

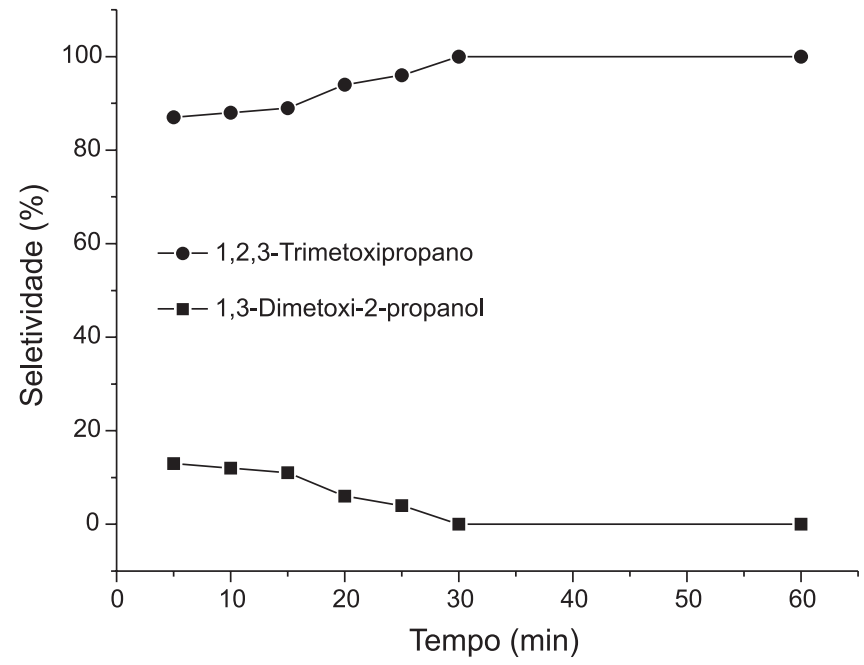

Figura 11. Distribuição de produtos na reação da glicerina bruta, oriunda da transesterificação do óleo de soja, com sulfato de metila

A preparação de 1-alquil-glicerol éteres, com alta pureza, pode ser realizada a partir do solketal, que é o nome comercial do cetal formado na reação do glicerol com acetona. Este produto é uma forma protegida do glicerol, onde uma das hidroxilas terminais e a central estão protegidas. Queste e colaboradores ${ }^{33}$ produziram 1-alquil-glicerol monoéteres pelo tratamento do solketal com halogenetos de alquila sob condições alcalinas (Figura 12). Após hidrólise ácida do produto formado, o 1-alquil-glicerol monoéter pode ser isolado do meio reacional, em rendimentos que variam de 35 a $63 \%$, em função do tamanho da cadeia. Os 1-alquil-glicerol monoéteres têm potencial de aplicação como solvossurfactantes, que apresentam propriedades para

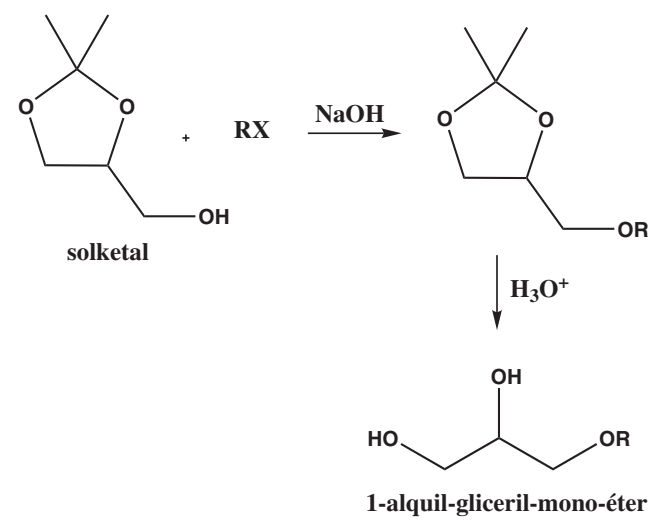

Figura 12. Produção seletiva de 1-alquil-glicerol-monoéteres 
dissolução de compostos orgânicos e inorgânicos, com usos diversos, em desengraxantes, perfumes, tintas e outras formulações.

A oligomerização do glicerol leva a éteres com potencial aplicação como surfactantes não iônicos de ampla aplicação em cosmética e na indústria alimentícia. ${ }^{34} \mathrm{O}$ tratamento do glicerol com catalisadores básicos em temperaturas da ordem de $200{ }^{\circ} \mathrm{C}$ leva a misturas de diglicerol, triglicerol e outros oligômeros ${ }^{35} \mathrm{Em}$ geral, a hidroxila primária é mais reativa e, normalmente, o dímero advindo da reação entre elas é o produto principal. Entretanto, também ocorre formação dos éteres advindos da condensação entre hidroxilas primária-secundária, secundária-secundária e até mesmo éteres cíclicos (Figura 13). Em geral, catalisadores homogêneos, como hidróxidos e carbonatos de sódio e potássio, apresentam melhores rendimentos nos poligliceróis, mas o emprego de catalisadores heterogêneos básicos, tais como resinas de troca iônica, zeólitas trocadas com cátions alcalinos e sílica mesoporosa, tem crescido nos últimos tempos. O uso de catalisadores heterogêneos pode alterar a seletividade dos poliglicerois formados, levando à maior seletividade no éter advindo da condensação com a hidroxila secundária do glicerol.

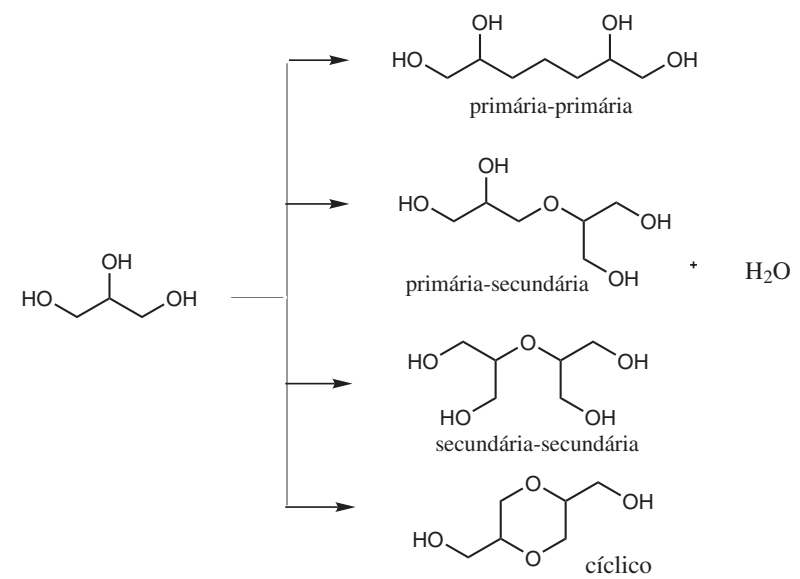

Figura 13. Possíveis produtos de dimerização do glicerol

\section{PRODUÇÃO DE ÉSTERES DE GLICERINA}

Os mono e diésteres do glicerol (mono e diacilglicerois) ocorrem naturalmente em gorduras que foram parcialmente hidrolisadas. Os de alta massa molecular são solúveis em óleo e insolúveis em água. Os triacilglicerois são componentes primários das gorduras e óleos vegetais.

Os mono e diacilglicerois são bastante utilizados como surfactantes. A produção seletiva de monoacilglicerois é normalmente realizada em três etapas. ${ }^{36}$ Inicialmente duas hidroxilas do glicerol são protegidas pela reação com acetona para formar o cetal. Em seguida, ocorre uma transesterificação com um éster de ácido graxo para funcionalização da hidroxila livre do cetal do glicerol (solketal). Por fim, o cetal é hidrolisado para formar o monoacilglicerol (Figura 14).

Cho e colaboradores ${ }^{37}$ sintetizaram mono e di ésteres do glicerol utilizando catálise ácida na reação com ésteres de ácidos carboxílicos alifáticos. Vários parâmetros foram estudados para otimizar o rendimento dos produtos. O primeiro parâmetro estudado foi o efeito da quantidade molar do substrato. As reações foram feitas variando-se a proporção molar de glicerol/éster, sendo que numa razão de 4:1 o monoéster foi formado com rendimento de $60 \%$, após $8 \mathrm{~h}$ de reação. A conversão, entretanto, caiu quando a razão molar excedeu 4:1. A temperatura também interfere no rendimento dos ésteres de glicerol. Em temperaturas mais altas há formação mais rápida do diacilglicerol. A água também afeta o rendimento dos produtos, já que a esterificação

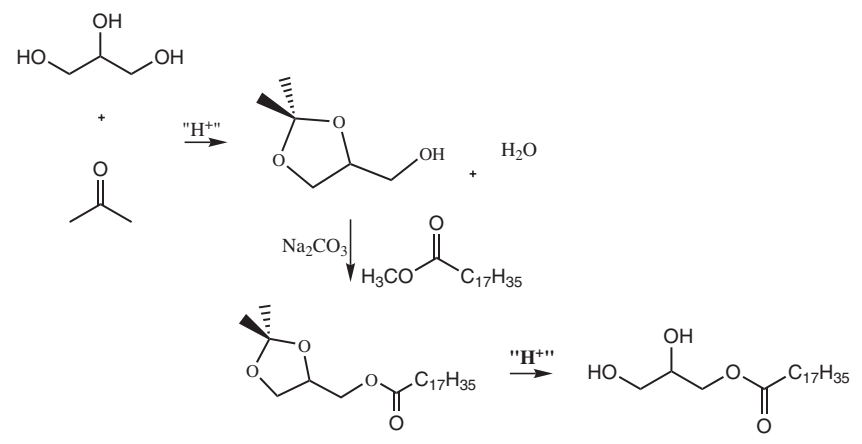

Figura 14. Produção seletiva de monoacilglicerois usando grupo de proteção

é reversível. O equilíbrio pode ser deslocado pela remoção da água do meio reacional com o uso de peneiras moleculares ou solventes apropriados para fazerem mistura azeotrópica.

A esterificação direta do glicerol com ácidos carboxílicos, em geral, resulta em mistura de isômeros, além da formação de di e triglicerídeos, que muitas vezes são difíceis de serem separados. Kharchafi e colaboradores ${ }^{38}$ relataram um método de produção seletiva de monoacilglicerois pela transesterificação direta do glicerol com ésteres metílicos de cadeia longa, utilizando P1 fosfazeno (BEMP) como catalisador e acetonitrila como solvente (Figura 15). A Tabela 1 mostra alguns resultados de conversão e seletividade. Os monoacilglicerois podem ser obtidos em altos rendimentos, e isentos de contaminação com os diacilglicerois, em proporções molares glicerol/éster acima de 2. Surpreendentemente, em menores proporções molares há formação do diacilglicerídeo, devido à maior solubilidade do monoacilglicerol no meio reacional, o que possibilita uma segunda esterificação. Em maiores proporções molares glicerol/éster, o monoacilglicerol precipita no meio reacional e pode ser isolado com alta pureza. A esterificação forma quase que exclusivamente o 1-acilglicerol.

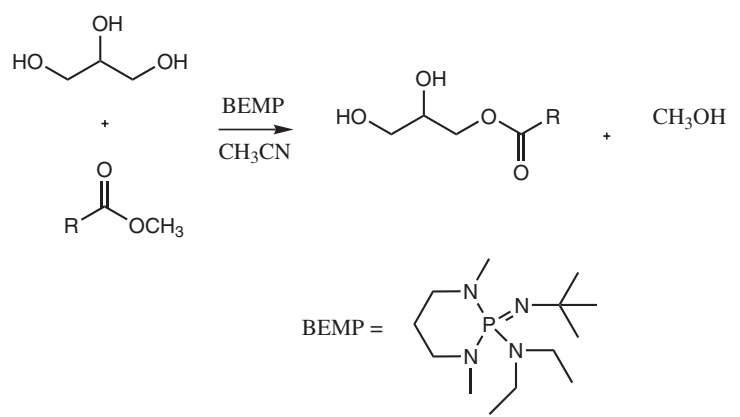

Figura 15. Esterificação seletiva do glicerol usando P1 fosfazeno (BEMP) como catalisador

Tabela 1. Transesterificação do glicerol na presença de P1 fosfazeno $^{38}$

\begin{tabular}{lccc}
\hline Éster graxo & $\begin{array}{c}\text { Proporção } \\
\text { molar glicerol/ } \\
\text { ácido }\end{array}$ & $\begin{array}{c}\% \text { Monoacilglicerol } \\
(\% \text { 1-monoéster })\end{array}$ & $\begin{array}{c}\% \text { Diacilglicerol } \\
(\% \text { 1,3-diéster })\end{array}$ \\
\hline Láurico & 5 & $45(85)$ & - \\
Mirístico & 5 & $79(100)$ & - \\
Palmítico & 5 & $78(100)$ & - \\
Palmítico & 0,5 & - & $80(99)$ \\
Esteárico & 2 & $86(100)$ & - \\
Esteárico & 1,5 & - & $81(100)$ \\
\hline
\end{tabular}


A esterificação direta do glicerol com ácidos carboxílicos pode ser efetuada com o uso de catalisadores ácidos heterogêneos. $\mathrm{Na}$ esterificação do glicerol com ácido oleico, o uso de resina ácida Amberlyst-31 como catalisador levou a uma conversão de $54 \%$ e $90 \%$ de seletividade ao monoacilglicerol. ${ }^{39}$ Entretanto, as condições reacionais são um pouco drásticas, com temperatura de $90{ }^{\circ} \mathrm{C}$, razão molar glicerol/ácido carboxílico de 6 e 24 h de reação. As zeólitas também foram testadas na esterificação do glicerol com ácido láurico. $^{40} \mathrm{O}$ monoacilglicerol foi obtido em $65 \%$ de seletividade, para $15 \%$ de conversão de glicerol, com o uso de zeólita Beta. Uma seletividade de $80 \%$ no monoacilglicerol pode ser alcançada com o uso de zeólita Y, mas com uma conversão de somente $6 \%$. Estes resultados foram obtidos para uma razão molar glicerol/ácido de 1.

$\mathrm{O}$ uso de sílica mesoporosa sulfonada (MCM-41-SO $\mathrm{S}_{3} \mathrm{H}$ também foi investigado na esterificação de ácido láurico com glicerol. ${ }^{41} \mathrm{Os}$ melhores resultados foram obtidos quando a superfície da sílica foi hidrofobizada, pela precipitação do precursor da sílica na presença de metil-trimetóxi-silano. Este procedimento elimina a quase totalidade dos grupos hidroxila da superfície da sílica mesoporosa, tornando-a hidrofóbica. Isto melhora a difusão do ácido graxo para o interior dos poros, aumentando a seletividade no monoacilglicerol. Nos catalisadores não hidrofobizados acredita-se que a reação se passe na superfície externa, ou na boca dos poros, levando a uma menor seletividade ao monoacilglicerol.

As acetinas são mono, di e triacetatos do glicerol. A monoacetina (monoacetato de glicerol) é um líquido higroscópico denso, vendido para uso em fabricação de explosivos, como agente gelatinizante e como solvente para tinturas. A diacetina (diacetato de glicerol) é um liquido higroscópico e é vendido em grau técnico para uso como lubrificante, agente amaciante e solvente. A triacetina (triacetato de glicerol) é usada como plastificante de celulose na fabricação de filtros de cigarros; seu segundo maior uso é como componente ligante para combustíveis sólidos de foguetes. Elas ainda são usadas como fixador de perfumes, na fabricação de cosméticos e como veículo em composição de fungicidas.

Gelosa e colaboradores ${ }^{42}$ avaliaram um novo método para síntese química utilizando reatores cromatográficos. Eles estudaram a síntese da triacetina pela esterificação do glicerol com ácido acético. Isto requer uma série de três passos de esterificação, cada um produzindo uma molécula de água como subproduto, estando a monoacetina e a diacetina como intermediários. O uso dos reatores cromatográficos permitiu a produção de quantidades significativas dos intermediários, em pureza suficiente para estimular novas aplicações. A produção da triacetina é dificultada em função das três reações em série e das condições de equilíbrio, que são particularmente desfavoráveis.

Mota e colaboradore ${ }^{43}$ investigaram a acetilação da glicerina com ácido acético catalisada por diferentes sólidos ácidos, (Figura 16). As reações foram feitas em condições de refluxo $\left(120-140{ }^{\circ} \mathrm{C}\right)$ em regime descontínuo, analisando a conversão do glicerol e a seletividade aos diversos produtos, notadamente mono, di e triacetina. Os resultados

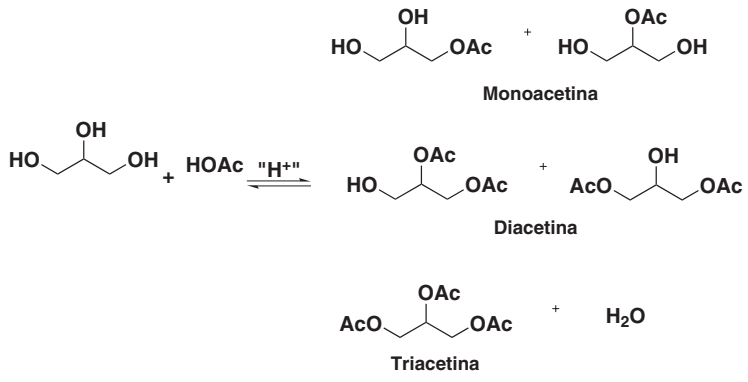

Figura 16. Acetilação do glicerol com ácido acético mostraram que a resina ácida Ambertlyst- 15 foi o catalisador mais ativo, com uma conversão de $97 \%$. Na sequência vieram a argila K-10 Montmorillonita, ácido nióbico e as zeólitas HZSM-5 e HUSY. Estas últimas apresentaram os piores desempenhos, provavelmente devido a questões difusionais e desativação do sítio ativo pela água formada. A seletividade variou para cada catalisador em função, também, do grau de conversão. Porém, nota-se que ocorre formação gradativa dos produtos di e triacetilados com o aumento da conversão e tempo de reação. Em todos os casos foi observada, também, a formação da $\alpha$-hidroxi-acetona (acetol), oriunda da desidratação da hidroxila terminal do glicerol.

Melero e colaboradores ${ }^{44}$ estudaram a atividade e seletividade a di e triacetina na reação do glicerol com ácido acético, usando materiais mesoestruturados sulfonados como catalisador. Os resultados mostraram valores superiores a $90 \%$ de conversão do glicerol e $80 \%$ de seletividade à di e triacetina depois de $4 \mathrm{~h}$ de reação. A força ácida do ácido sulfônico foi um fator importante, afetando o desempenho catalítico desses materiais.

A triacetina tem sido testada como aditivo a combustíveis, sobretudo o biodiesel, melhorando a viscosidade e a fluidez. ${ }^{20,45}$ Por exemplo, a adição de apenas $1 \%$ de triacetina ao biodiesel oriundo de óleo de canola, diminui em $9{ }^{\circ} \mathrm{C}$ o seu ponto de congelamento.

\section{DESIDRATAÇÃO DE GLICERINA (ACROLEÍNA E ÁCIDO ACRÍLICO)}

A desidratação da glicerina pode ocorrer de dois modos. A desidratação da hidroxila central do glicerol leva ao 3-hidroxi-propanal, o qual também pode sofrer desidratação para formar a acroleína. A desidratação da hidroxila terminal leva à $\alpha$-hidroxi-acetona, também conhecida como acetol (Figura 17).
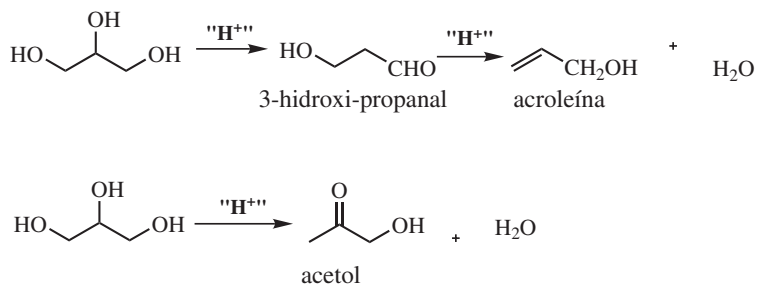

Figura 17. Desidratação da glicerina

O tratamento de uma solução aquosa de glicerol com ácido sulfúrico na temperatura de $300{ }^{\circ} \mathrm{C}$ e pressão de $34,5 \mathrm{MPa}$ leva à formação de acroleína em $84 \%$ de seletividade, para uma conversão de $40 \% .{ }^{46}$ A conversão pode ser aumentada para $90 \%$ com o uso de condições supercríticas. ${ }^{47}$ Recentemente, o estudo de catalisadores ácidos heterogêneos para a desidratação do glicerol tornou-se mais relevante. Chai e colaboradores ${ }^{48}$ estudaram a desidratação do glicerol em fluxo contínuo e temperaturas da ordem de $300{ }^{\circ} \mathrm{C}$. Eles relataram que as melhores seletividades para acroleína, entre 60 e $70 \%$, são obtidas com catalisadores contendo função acidez de Hammett (Ho) entre -3,0 e -8,2, tais como zeólita HZSM-5, ácido nióbico e heteropoliácidos. Catalisadores com Ho menor que -8,2, como zircônia sulfatada e zeólita $\beta$, apresentaram muitas reações laterais, diminuindo a seletividade para 30\%, aproximadamente. Já sólidos com Ho maior que -3,0, como o óxido de cério e o óxido de lantânio, apresentam baixa atividade catalítica. Cabe salientar que as medidas de função acidez de Hammett para os sólidos testados são muito mais qualitativas que quantitativas, já que é muito difícil quantificar o equilíbrio ácido-base sobre a superfície de um sólido. Em um trabalho posterior, o mesmo grupo estudou ${ }^{49}$ o uso de heteropoliácidos $\left(\mathrm{H}_{3} \mathrm{PW}_{12} \mathrm{O}_{40}\right)$ suportados em sílica e zircônia. 
Os resultados mostraram que o material suportado em sílica é destruído nas condições reacionais, mas o heteropoliácido suportado em zircônia permanece ativo por um período de pelo menos $10 \mathrm{~h}$, apresentando uma seletividade de $70 \%$ para acroleína, com $54 \%$ de conversão do glicerol. Em outro estudo ${ }^{50}$ foi mostrado que heteropoliácidos de fósforo-molibdênio $\left(\mathrm{H}_{3} \mathrm{PMo}_{12} \mathrm{O}_{40}\right)$ são menos estáveis na reação de desidratação do glicerol que os heteropoliácidos de fósforo-tungstênio $\left(\mathrm{H}_{3} \mathrm{PW}_{12} \mathrm{O}_{40}\right)$. Tsukuda e colaboradores ${ }^{51}$ mostraram que heteropoliácidos $\left(\mathrm{H}_{3} \mathrm{PW}_{12} \mathrm{O}_{40}\right)$ suportados em uma sílica mesoporosa são particularmente ativos e seletivos à acroleína. A $275^{\circ} \mathrm{C}$, e em condições de fluxo, eles observaram $86 \%$ de seletividade à acroleína, para uma conversão de glicerol de $98 \%$. Estes dados indicam que o modo de preparo e de imobilização do heteropoliácido têm grande influência na conversão, seletividade e estabilidade do catalisador. É importante salientar que em todos estes estudos o acetol foi observado como subproduto, mostrando que as duas rotas de desidratação do glicerol estão operantes nestes catalisadores.

A acroleína é um importante intermediário para a produção de ácido acrílico, que por sua vez é utilizado na produção de polímeros super absorventes para uso em fraldas descartáveis, tintas, adesivos, objetos decorativos, entre outros. A acroleína é também usada na produção da metionina, aminoácido empregado na indústria alimentícia.

A produção de ácido acrílico envolve, numa primeira etapa, a oxidação do propeno a acroleína, sobre catalisadores à base de bismuto e molibdênio. Numa segunda etapa, ocorre a oxidação ao ar da acroleína formada, sobre óxidos mistos de vanádio e molibdênio como catalisadores. ${ }^{52} \mathrm{Um}$ desafio interessante é o desenvolvimento de um processo de transformação química da glicerina em ácido acrílico, em uma só etapa, englobando catalisadores capazes de desidratar o glicerol e oxidar a acroleína formada até ácido acrílico (Figura 18). A maior parte destes estudos está descrita na forma de patentes, ${ }^{53}$ que em geral utilizam mistura de catalisadores ácidos e de oxidação. Os resultados obtidos mostram que a seletividade ao ácido acrílico ainda é baixa, na faixa de 5 a $10 \%$, havendo uma grande oportunidade de desenvolvimento neste campo. Vale salientar que o Brasil não possui fábrica de produção de ácido acrílico e que o desenvolvimento de um processo deste tipo, a partir da glicerina oriunda da produção de biodiesel, pode resultar em uma grande economia de divisas.

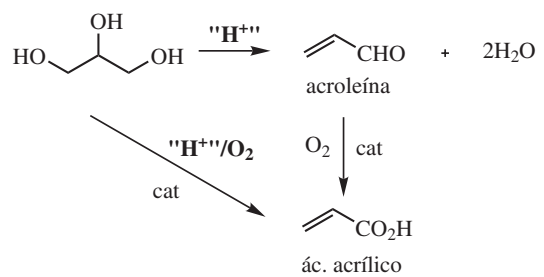

Figura 18. Desidratação oxidativa de glicerol a ácido acrílico

\section{HIDROGENÓLISE DA GLICERINA}

Uma das reações de transformação química do glicerol mais estudadas na literatura é a hidrogenólise a 1,2 e 1,3 propanodiol (1,2 PD e 1,3 PD). O primeiro produto, também conhecido como propileno-glicol, tem aplicação como agente anticongelante e na produção de polímeros. Já o 1,3 PD é utilizado na produção de fibras sintéticas de poliésteres.

A hidrogenólise de uma solução aquosa de glicerol a $180^{\circ} \mathrm{C}$ e 80 barr na presença de catalisadores de $\mathrm{Cu}, \mathrm{Pd}$, Ru suportados em $\mathrm{ZnO}$, carvão ativo ou $\mathrm{Al}_{2} \mathrm{O}_{3}$ produz 1,2 $\mathrm{PD}$ e 1,3 $\mathrm{PD}$ com boa seletividade. ${ }^{54}$ A seletividade ao 1,2 PD aumentou significativamente na presença da combinação de $\mathrm{CuO} / \mathrm{ZnO}$, utilizando água como solvente. Para uma boa seletividade ao 1,3 PD, os estudos com o catalisador de $\mathrm{Rh} / \mathrm{C} \mathrm{em}$ sulfolana como solvente apresentaram os melhores resultados. A adição de ácido tungstênico $\left(\mathrm{H}_{2} \mathrm{WO}_{4}\right)$ ajudou a melhorar a seletividade, possivelmente auxiliando em uma etapa de desidratação. Entretanto, esta etapa não parece ser a mais crítica no processo, já que a adição de $\mathrm{HCl}$ levou a menores conversões. Kusunoki e colaboradores ${ }^{55,56}$ relataram que o uso combinado de catalisador de Ru suportado em carvão ativo e resina ácida Amberlyst-15 melhora a atividade para a hidrogenólise de solução aquosa de glicerol a $120^{\circ} \mathrm{C}$ e $4 \mathrm{MPa}$ de pressão, reforçando a hipótese de um mecanismo reacional envolvendo etapa de desidratação do glicerol. A Figura 19 mostra um possível mecanismo para a hidrogenólise do glicerol a 1,2 e 1,3 PD. Entretanto, outras propostas mecanísticas aparecem na literatura. ${ }^{57}$

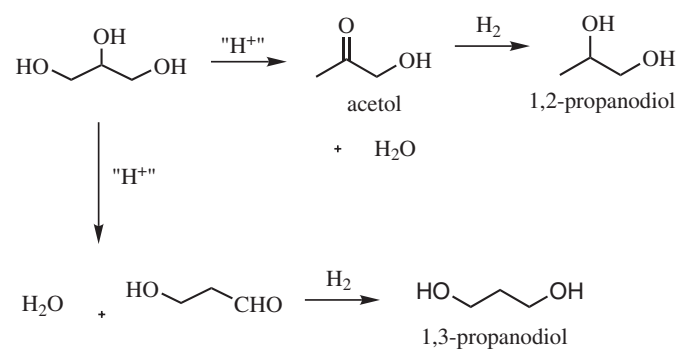

Figura 19. Possível esquema mecanístico para a hidrogenólise do glicerol

Dasari e colaboradores ${ }^{58}$ estudaram a hidrogenólise do glicerol a $200{ }^{\circ} \mathrm{C}$ e 13,8 bar de pressão sobre diversos catalisadores metálicos suportados. Os melhores resultados foram com cromito de cobre, onde conseguiram uma conversão de $55 \%$ e $85 \%$ de seletividade a propileno glicol. O acetol foi também formado em todas as reações, sugerindo que ele possa ser um intermediário na hidrogenólise do glicerol a 1,2 PD, conforme mostrado na Figura 19. O níquel de Raney também se mostrou ativo na hidrogenólise do glicerol a 1,2 PD, com $71 \%$ de seletividade a $97 \%$ de conversão. O etanol foi também observado como produto, numa seletividade de $19 \%$, indicando que ocorre alguma clivagem da ligação C-C da molécula.

A hidrogenólise do glicerol sobre condições mais severas pode levar a outros produtos. Casale e Gomez ${ }^{59}$ descreveram um método de hidrogenólise da glicerina a propanol utilizando catalisadores de cobre e zinco numa pressão de 2175 psi e temperaturas na faixa de 240-270 ${ }^{\circ} \mathrm{C}$. Ludvig e Manfred ${ }^{60}$ descreveram um outro método para produção de isopropanol, n-propanol e propanodiois utilizando catalisadores metálicos contendo cobalto, cobre, manganês ou molibdênio suportados e um poliácido inorgânico. $\mathrm{O}$ rendimento obtido foi de $95 \%$, à pressão de 3625 psi e temperatura de $250{ }^{\circ} \mathrm{C}$.

Uma aplicação interessante para a hidrogenólise da glicerina é numa rota para produção de propeno. Este produto é um importante insumo na produção de plásticos e consumido em larga escala no Brasil. Ele é, normalmente, produzido a partir da nafta petroquímica, pelo processo de craqueamento a vapor, e há previsões para uma demanda crescente, que deverá ultrapassar a oferta deste produto no mercado nacional no início da próxima década, ocasionando problemas na balança de pagamentos. O glicerol pode ser transformado em propeno, ${ }^{61}$ através de uma reação de hidrogenólise sobre catalisadores específicos (Figura 20). A conversão é completa e o propeno é formado com seletividade de cerca de $90 \%$.

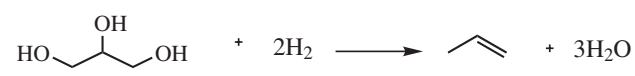

Figura 20. Hidrogenólise do glicerol a propeno 


\section{OXIDAÇÃO DA GLICERINA}

A oxidação do glicerol pode produzir diversos compostos (Figura 21).

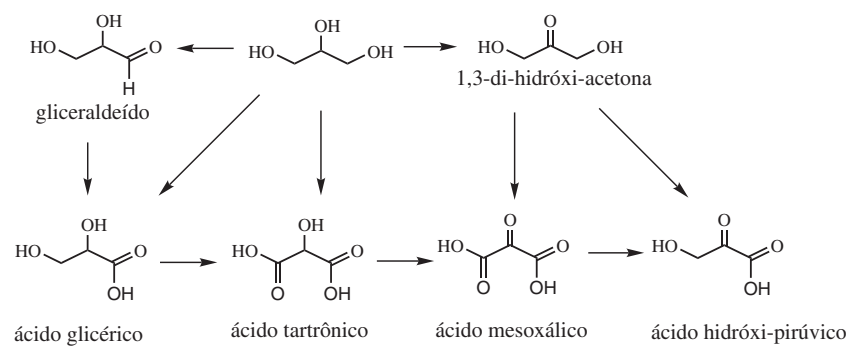

Figura 21. Produtos de oxidação do glicerol

A 1,3-di-hidróxi-acetona (DHA) é utilizada em bronzeadores e também na produção de polímeros. O método mais tradicional de produção envolve a fermentação do glicerol com Gluconobacter oxydans..$^{62} \mathrm{Um}$ método alternativo e interessante de produção desta substância envolve a oxidação eletrocatalítica do glicerol. ${ }^{63}$ Em menores tempos de reação há formação seletiva da DHA. Com maiores tempos de oxidação ocorre também a formação do ácido hidróxi-pirúvico (HPA).

O gliceraldeído é um intermediário no metabolismo de carboidratos. Ele pode ser produzido pela oxidação do glicerol sobre catalisadores de platina, que são mais efetivos para a oxidação da hidroxila primária. Por exemplo, o gliceraldeído é produzido com $55 \%$ de seletividade e $90 \%$ de conversão em catalisadores de Pt/C. ${ }^{64}$ A seletividade a DHA é de somente $12 \%$. Entretanto, a seletividade para oxidação da hidroxila secundária aumenta com a adição de $\mathrm{Pb}$ ou $\mathrm{Bi}$ ao catalisador de Pt. ${ }^{65,66}$

O ácido glicérico pode ser obtido em $77 \%$ de seletividade e $90 \%$ de conversão de glicerol na presença de catalisadores de paládio. ${ }^{62}$ Outros produtos da reação são a DHA, ácido tatrônico e ácido oxálico, indicando que ocorre alguma clivagem da ligação $\mathrm{C}-\mathrm{C}$ nas condições reacionais. O uso de ligas metálicas de $\mathrm{Au} / \mathrm{Pt}$ e Au/Pd mostraram-se bastante ativas para a oxidação do glicerol. ${ }^{67} \mathrm{~A}$ Tabela 2 mostra alguns resultados, comparando-se a frequência de repetição da reação (turnover - TOF) com o dos catalisadores monometálicos. Observa-se um aumento considerável no TOF com o uso do sistema bimetálico, sem alterações significativas na seletividade.

Hutchings e colaboradores ${ }^{68}$ relataram a oxidação do glicerol com água oxigenada, na presença de metalossilicatos ${ }^{69}$ contendo titânio, vanádio e ferro na estrutura porosa. Os produtos principais, independentemente do grau de conversão, foram ácido fórmico e formiatos de glicerol. Estes resultados mostram que estes catalisadores são muito ativos para oxidação do glicerol, levando a produtos de clivagem da ligação C-C.

\section{OUTRAS TRANSFORMAÇÕES DO GLICEROL}

O glicerol pode ser convertido em gás de síntese (uma mistura de $\mathrm{CO}$ e $\mathrm{H}_{2}$ ), pelo tratamento em catalisadores de $\mathrm{Pt}$ suportada em $\mathrm{CeO}_{2} /$ $\mathrm{ZrO}_{2}$ (Figura 22). ${ }^{70} \mathrm{O}$ interessante neste estudo é que altas conversões são obtidas em temperaturas da ordem de $350^{\circ} \mathrm{C}$, apesar da reação ser endotérmica por $83 \mathrm{kcal} / \mathrm{mol}$. O gás de síntese tem inúmeras aplicações industriais, como a síntese de metanol, que poderia ser novamente utilizado em processos de transesterificação de óleos vegetais para produzir biodiesel, na reação de deslocamento, que é utilizada para gerar hidrogênio para uso em células a combustível ou na síntese de amônia, e no processo de Fischer-Tropsch, para produção de hidrocarbonetos, sobretudo na faixa do óleo diesel. A combinação dos dois processos ${ }^{71}$ (geração de gás de síntese e FischerTropsch), permite otimizar o fluxo energético, já que a segunda reação é exotérmica.

$$
\underbrace{\mathrm{OH}}_{\mathrm{HO}} \mathrm{OH}+4 \mathrm{CO}+4 \mathrm{H}_{2} \quad \Delta \mathrm{H}=+83 \mathrm{kcal} / \mathrm{mol}
$$

Figura 22. Gaseificação do glicerol

O tratamento do glicerol com ácido clorídrico concentrado, na presença de ácidos de Lewis como catalisadores, permite obter-se uma mistura do 1,2-dicloro-3-propanol e 1,3-dicloro-2-propanol, que submetidos ao tratamento com solução alcalina fornecem a epiclorodrina (Figura 23). A Solvay desenvolveu este processo ${ }^{72}$ para produção da epicloridrina, que é um intermediário usado na produção de resinas e polímeros.

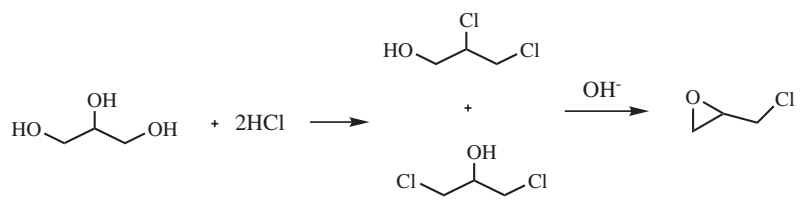

Figura 23. Rota tecnológica de transformação do glicerol a epicloridrina

O carbonato de glicerina é um produto com aplicações diversas, que pode ser usado como solvente industrial e monômero na preparação de policarbonatos, poliésteres, poliuretanas e poliamidas. Uma das rotas mais utilizadas de produção deste composto envolve a reação do glicerol com carbonatos cíclicos, como o carbonato de etileno e propileno. ${ }^{73}$ Estes últimos são normalmente produzidos pela reação do $\mathrm{CO}_{2}$ com óxido de etileno ou propileno.

A carboxilação do glicerol com $\mathrm{CO}_{2}$ supercrítico já foi relatada na literatura. ${ }^{74} \mathrm{~A}$ conversão, entretanto, não é muito alta, obtendose melhores rendimentos do carbonato de glicerina na presença de zeólita 13X como catalisador. Compostos organo-estanho também agem como catalisadores para a carboxilação do glicerol. O n$\mathrm{Bu}_{2} \mathrm{Sn}\left(\mathrm{OCH}_{3}\right)_{2}$ foi o que apresentou maior atividade. ${ }^{75,76}$

Tabela 2. Oxidação do glicerol sobre catalisadores metálicos a $50{ }^{\circ} \mathrm{C}$

\begin{tabular}{|c|c|c|c|c|c|c|}
\hline \multirow{2}{*}{ Catalisador } & \multirow{2}{*}{ Conv. (\%) } & \multicolumn{4}{|c|}{ Seletividade $\%$} & \multirow{2}{*}{ TOF $\left(h^{-1}\right)$} \\
\hline & & Ác. glicérico & Ác. glicólico & Ác. oxálico & Ác. tartrônico & \\
\hline $\mathrm{Pt} / \mathrm{C}$ & 50 & 42 & 31 & 8 & 6 & 532 \\
\hline $\mathrm{Pd} / \mathrm{C}$ & 50 & 81 & 3 & 0 & 14 & 1151 \\
\hline $\mathrm{Au} / \mathrm{C}$ & 50 & 65 & 12 & 10 & 9 & 1090 \\
\hline $\mathrm{Au}-\mathrm{Pt} / \mathrm{C}$ & 50 & 72 & 18 & 1 & 8 & 1987 \\
\hline $\mathrm{Au}-\mathrm{Pd} / \mathrm{C}$ & 50 & 77 & 5 & 0 & 18 & 1775 \\
\hline
\end{tabular}


Uma outra rota tecnológica de produção do carbonato de glicerina envolve a reação da uréia com glicerol, na presença de ácidos de Lewis como catalisadores. ${ }^{77} \mathrm{O}$ inconveniente neste processo são os longos tempos de reação (entre 6 e $8 \mathrm{~h}$ ) e as altas temperaturas (cerca de $160{ }^{\circ} \mathrm{C}$ ). A reação provavelmente se passa pela complexação inicial do ácido de Lewis com a uréia, permitindo o ataque nucleofílico do glicerol à carbonila e subsequente eliminação de amônia. Mota e colaboradores ${ }^{78}$ desenvolveram uma nova rota para produzir o carbonato de glicerina, de maneira mais rápida e em condições reacionais mais brandas, reagindo glicerol com o N,N'-Carbonil-di-Imidazol (CDI). Essa reação ocorre à temperatura ambiente e em apenas 15 min (Figura 24). A glicerina bruta, proveniente da produção do biodiesel, pode ser utilizada sem qualquer purificação, já que a alcalinidade decorrente da solubilização do catalisador de trasnsesterificação ajuda na formação do alcóxido de glicerina, aumentando a reatividade. A reação se processa sem a necessidade de catalisador, pois a carbonila do CDI já é bastante ativada para o ataque nucleofílico, em função de não haver ressonância com o par de elétrons do átomo de nitrogênio do anel do imidazol. Este par de elétrons faz parte da nuvem $\pi$ do anel aromático do grupamento imidazol e, desta maneira, não é disponível para interação com os orbitais da carbonila, tornando-a mais susceptível ao ataque nucleofílico.

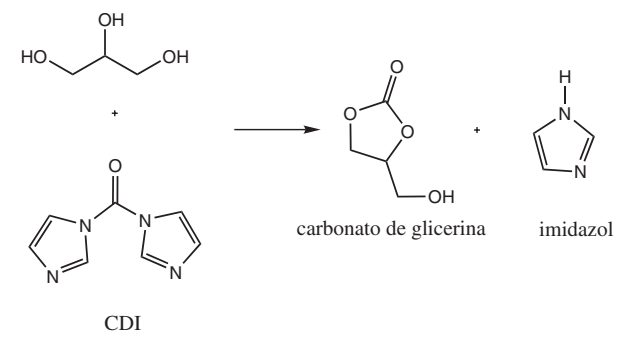

Figura 24. Reação do glicerol com CDI para produzir carbonato de glicerina

\section{CONSIDERAÇÕES FINAIS}

O glicerol pode ser transformado em éteres, acetais e ésteres com grandes aplicações industriais, sobretudo para o setor de combustíveis. Os éteres oriundos da reação do glicerol com isobuteno são potenciais aditivos para diesel e biodiesel. A produção de éteres do glicerol pela reação com alcoóis primários, como o etanol, ainda é pouco estudada. Estes éteres têm potencial para mistura em combustíveis, sendo oriundos de matéria-prima $100 \%$ renovável. Os acetais e cetais da glicerina também podem ser misturados a combustíveis, sobretudo ao diesel e biodiesel visando a melhoria de propriedades de fluidez e diminuição de particulados. Uma vantagem adicional dos acetais e cetais é que possuem uma hidroxila livre, que pode ser funcionalizada para agregar outros grupos, com diferentes aplicações, à molécula. Já os monoacilglicerídeos podem ser produzidos em bons rendimentos pela esterificação e transesterificação do glicerol. As acetinas, ou acetatos do glicerol, têm inúmeras aplicações, incluindo a mistura com biodiesel.

A hidrogenólise do glicerol tem sido utilizada para produção do 1,2 e 1,3-propanodiol, produtos de grande importância na indústria química. A alteração das condições reacionais e dos catalisadores pode levar a produtos de hidrogenólise mais profunda, como isopropanol e propeno. O grande desafio é o desenvolvimento de processos contínuos e operando a pressões mais baixas.

Produtos de desidratação e de oxidação do glicerol também têm grande valor comercial. A acroleína pode ser produzida na desidratação do glicerol sobre catalisadores ácidos, como $\mathrm{H}_{2} \mathrm{SO}_{4}$, zeólitas, ácido nióbico e heteropoliácidos. O uso de catalisadores heterogêneos vem ganhando força a cada dia, mas ainda é necessário melhorar a estabilidade, pois muitos sistemas sofrem desativação, ou são destruídos durante a reação. Um desafio tecnológico importante é o desenvolvimento de processo para produção do ácido acrílico em uma única etapa a partir do glicerol. Isto teria que envolver catalisadores bifuncionais, que possam desidratar seletivamente o glicerol a acroleína e oxidar esta a ácido acrílico. Vale salientar que o Brasil não possui unidade industrial de produção deste insumo, que é largamente utilizado na fabricação de polímeros. Outros produtos importantes de oxidação do glicerol são a di-hidróxi-acetona, usada em bronzeadores, e o ácido hidróxi-pirúvico.

A produção de gás de síntese a partir do glicerol é uma alternativa bastante interessante, sobretudo se a reação for acoplada a um processo Fischer-Tropsch para produção de hidrocarbonetos na faixa da gasolina e do diesel, pois melhora significativamente o balanço energético.

O carbonato de glicerina é um produto que vem ganhando novas aplicações comerciais a cada dia. A carboxilação direta do glicerol com dióxido de carbono ainda é um processo complexo, levando a conversões modestas. Existe muito espaço para o desenvolvimento de sistemas catalíticos que permitam a carboxilação direta com $\mathrm{CO}_{2}$. Métodos indiretos, utilizando uréia e CDI, mostraram-se mais eficientes, mas são de maior custo e podem ser otimizados para produzir o carbonato de forma mais barata.

A gliceroquímica oferece aos químicos e engenheiros químicos inúmeras oportunidades; quer no desenvolvimento de novos produtos, processos e aplicações, ou na síntese de novos catalisadores, mais ativos e seletivos. O grande volume de glicerina oriunda da produção de biodiesel, tanto no Brasil, como no mundo, será uma fonte abundante e barata de uma matéria-prima renovável nos próximos anos. Cabe a nós utilizarmos nossa criatividade e conhecimento para desenvolvermos aplicações economicamente viáveis e que possam beneficiar toda a sociedade.

\section{AGRADECIMENTOS}

Ao apoio financeiro da Repsol/YPF, Quattor Petroquímica, FINEP, CNPq, FAPERJ e PRH-ANP.

\section{REFERÊNCIAS}

1. Mota, C. J. A.; Tchê Química 2006, 3, 26.

2. Ribeiro, S. K.; Scientific American Brasil 2006, edição 53.

3. Shay, E. G.; Biomass Bioenerg. 1993, 4, 227.

4. Pinto, A. C.; Guarieiro, L. N.; Resende, M. J. C.; Ribeiro, N. M.; Torres, E. A.; Lopes, W. A.; Pereira, P. A D.; Andrade, J. B.; J. Braz. Chem. Soc. 2005, 16, 1313 .

5. Suarez, P. A. Z.; Meneguetti, S. M. P.; Quim. Nova 2007, 30, 2068.

6. Anuário da Indústria Química Brasileira 2005, São Paulo.

7. Zhou, C. H.; Beltramini, J. N.; Fan, Y. X.; Lu, G. Q.; Chem. Soc. Rev. 2008, 37, 527.

8. Knothe, G.; van Gerpen, J.; Krahl, J.; Ramos, L. P.; Manual do Biodiesel, Edgard Blücher: São Paulo, 2006, cap. 11.

9. Delfort, B.; Durand, I.; Jaecker, A.; Lacome, T.; Montagne, X.; Paille, F.; US pat. 2003/0163949 A1, 2003.

10. Dubois, J. L.; WO 2008/050030, 2008

11. Piasecki, A.; Sokolowski, A.; Burczyk,B.; Kotlewska U.; J. Am. Oil Chem. Soc. 1997, 74, 33.

12. Climent, M. J.; Veltry, A.; Corma, A.; Green Chem. 2002, 4, 565.

13. Sari, P.; Razzak, M.; Tucker, I. G.; Pharm. Dev. Technol 2004, 9, 97.

14. Deutsch, J.; Martin, A.; Lieske, H.; J. Catal. 2007, 245, 428.

15. da Silva, C. X. A.; Gonçalves, V. L. C.; Mota, C. J. A.; Green Chem. 2009, 11,38 . 
16. Okuhara, T.; Chem. Rev. 2002, 102, 3641.

17. Smit, B.; Maessen, T. L. M.; Nature 2008, 451, 671.

18. Chandrasekhar, S.; Chem. Soc. Rev. 1987, 16, 313.

19. Wessendorf, R.; Erdoel \& Kohle, Erdgas, Petrochemie 1995, 48, 138.

20. Garcia, E.; Laca, M.; Pérez, E.; Garrido, A.; Peinado, J.; Energy \& Fuels 2008, 22, 4274.

21. Delford, B.; Durand, I.; Jaecker, A.; Lacome, T.; Montagne, X.; Faille, F.; Fr pat 2833607, 2001.

22. Kousemaker, M. A.; WO pat. 2005/010131 A1, 2005

23. Piantadosi, C.; Anderson, C. E.; Brecht, E. A.; Yarbro, C. L.; J. Am. Chem. Soc. 1959, 80, 6613.

24. Showler, A. J.; Darley, P. A.; Chem. Rev. 1967, 67, 427.

25. Klepacova, K.; Mravec, D.; Hajekova, E.; Bajus, M.; Petroleum and Coal 2003, 45, 54.

26. Karinen, R. S.; Krause, A. O. I.; Appl. Catal. A 2003, 306, 128.

27. Klepacova, K.; Mravec, D.; Bajus, M.; Appl. Catal. A 2005, 294, 141.

28. da Silva, C. R. B.; Gonçalves, V. L. C.; Lachter, E. R.; Mota, C. J. A.; J. Braz. Chem. Soc. 2009, 20, 201.

29. Gu, Y.; Azzouzi, A.; Pouilloux, Y.; Jerome, F.; Barrault, J.; Green Chem. 2008, 10, 164.

30. Pinto, B. P.; Dissertação de Mestrado, Universidade Federal do Rio de Janeiro, Brasil, 2009.

31. March, J.; Advanced Organic Chemistry. Reactions, Mechanisms and Structure, $4^{\text {th }}$ ed., Wiley: New York, 1992, p. 386.

32. Mota, C. J. A.; Gonçalves, V. L. C.; Br PI 0700063-4, 2007.

33. Queste, S.; Bauduin, P.; Touraud, D.; Kunz, W.; Aubry, J. M.; Green Chem. 2006, 8, 822.

34. Barrault, J.; Jerome, F.; Pouilloux, Y.; Lipid Technol. 2005, 17, 131.

35. Márquez-Alvarez, C; Sastre, E.; Pérez-Pariente, J.; Topics Catal. 2004, 27, 105.

36. Jérôme, F.; Pouilloux, Y.; Barrault, J.; ChemSusChem 2008, 1, 586.

37. Cho, G. H. P.; Yeong, S. K.; Ool, T. L.; Chuah, C. H.; J. Surf. Deter. 2006, 9, 147.

38. Kharchafi, G.; Jérôme, F.; Douilez, J. P.; Barrault, J.; Green Chem. 2006, 8,710 .

39. Pouilloux, Y.; Abro, S.; Vanhove, C.; Barrault, J.; J. Mol. Catal. A 1999, 149, 243 .

40. Machado, M. S.; Pérez-Pariente, J.; Sastre, E.; Cardoso, D. S.; de Guerenu, A. M.; Appl. Catl. A 2000, 203, 321.

41. Diaz, I.; Marquez-Alvarez, C.; Mohino, F.; Pérez-Pariente, J.; Sastre, E.; J. Catal. 2000, 193, 295.

42. Gelosa, D.; Ramaioli, M.; Valente, G.; Morbidelli, M.; Ind. Eng. Chem. Res. 2003, 42, 6536.

43. Gonçalves, V. L. C.; Pinto, B. P.; Silva, J. C.; Mota, C. J. A.; Catal. Today 2008, 133-135, 673.

44. Melero, J. A.; van Grieken, R.; Morales, G.; Paniagua, M.; Energy \& Fuel 2007, 21, 1782.

45. Delagado, J.; Es Pat. 2201894, 2002

46. Ramaya, S.; Brittain, A.; de Almeida, C.; Mok, W.; Antal, M. J.; Fuel 1987, 66, 1363.

47. Watanabe, T.; Iida, Y.; Aizawa, T.; Ainda, M.; Inomata, H.; Bioresour. Technol. 2007, 98, 1285.

48. Chai, S. H.; Hang, H. P.; Liang, Y.; Xu, B. Q.; Green Chem. 2007, 9, 1130.
49. Chai, S. H.; Hang, H. P.; Liang, Y.; Xu, B. Q.; Green Chem. 2008, 10 , 1087.

50. Atia, H.; Armbruster, U.; Martin, A.; J. Catal. 2008, 258, 71.

51. Tsukuda, E.; Sato, S.; Takahashi, R.; Sodesawa, T.; Catal. Commun. 2007, 8, 1349.

52. Kampe, P.; Giebelder, L.; Smuelis, D.; Kunert, J.; Drochner, A.; Haass, F.; Adams, A. H.; Ott, J.; Endres, S.; Shimanke, G.; Buhrmester, T.; Martin, M.; Fuess, H.; Vogel, H.; Phys. Chem. Chem. Phys. 2007, 9, 3577.

53. Dubois, J. L.; Duquenne, C.; Holderich, W.; Fr pat. 2884818 A1, 2006.

54. Chaminand, J.; Djakovitch, L.; Gallezot, P.; Marion, P.; Pinel, C.; Rosierb, C.; Green Chem. 2004, 6, 359.

55. Kusunoki, Y.; Miyazawa, T.; Kunimori, K.; Tomishige, K.; Catal. Commun. 2005, 6, 645 .

56. Miyazawa, T.; Kusunoki, Y.; Kunimori, K.; Tomishige, K.; J. Catal . 2006, 240, 213.

57. Zheng, Y.; Chen, X.; Shen, Y.; Chem. Rev. 2008, 108, 5223.

58. Dasari, M.; Kiatsimkul, P. P.; Sutterlin, W. R.; Suppes, G. J.; Appl. Catal. A 2005, 281, 225.

59. Casale, B.; Gomez, A. M.; US pat 5,276,18, 1994

60. Ludwig, S.; Manfred, E.; US pat 5,616,817, 1997.

61. Oliveira, M.; Pesquisa FAPESP on line 2008, 149.

62. Bauer, R.; Hekmat, D.; Biotechnol. Prog. 2006, 22, 278.

63. Ciriminna, R.; Palmisano, G.; Della Pina, C.; Rossi, M.; Pagliaro, M.; Tetrahedron Lett. 2006, 47, 6993.

64. Garcia, R.; Besson, M.; Gallezot, P.; Appl. Catal. A 1995, 127, 165.

65. Fordham, P.; Besson, M.; Gallezot, P.; Appl. Catal. A 1995, 133, L179.

66. Mallat, T.; Baiker, A.; Catal. Today 1994, 19, 247

67. Bianchi, C. L.; Canton, P.; Dimitratos, N.; Porta, F.; Prati, L.; Catal. Today 2005, 102-103, 203.

68. McMorn, P.; Roberts, G.; Hutchings, G.; J. Catal. 1999, 63, 193

69. Luna, F. J.; Schuchardt, U.; Quim. Nova 2001, 24, 885.

70. Soares, R. R.; Simonetti, D. A.; Dumesic, J. A.; Angew. Chem., Int. Ed. 2006, 45, 3982.

71. Simonetti, D. A.; Rass-Hansen, J.; Kunkes, E. L.; Soares, R. R.; Dumesic, J. A ; Green Chem. 2007, 9, 1073.

72. Krafit, P.; Franck, C.; de Andolenko, I.; Veyrac, R.; US pat. 20080281132, 2008.

73. Mouloungui, Z.; Yoo, J. W.; Gachen, C. A.; Gaset. A.; EP pat 0739888 , 1996.

74. Vieville, C.; Yoo, J. W.; Pelet, S.; Mouloungui, Z.; Catal. Lett. 1998, 56, 245.

75. Aresra, M.; Dibenedetto, A.; Patore, C.; Catal. Today 2006, 115, 88.

76. Aresra, M.; Dibenedetto, A.; Nocito, F.; Patore, C.; J. Mol. Catal. A 2006, 257, 149.

77. Claude, S.; Mouloungui, Z.; Yoo, J. W.; Gaset, A.; EP pat 0955298 A1, 1999.

78. Mota, C. J. A.; Gonçalves, V. L. C.; Rodrigues, R. C.; Br PI 0706121-8, 2007. 